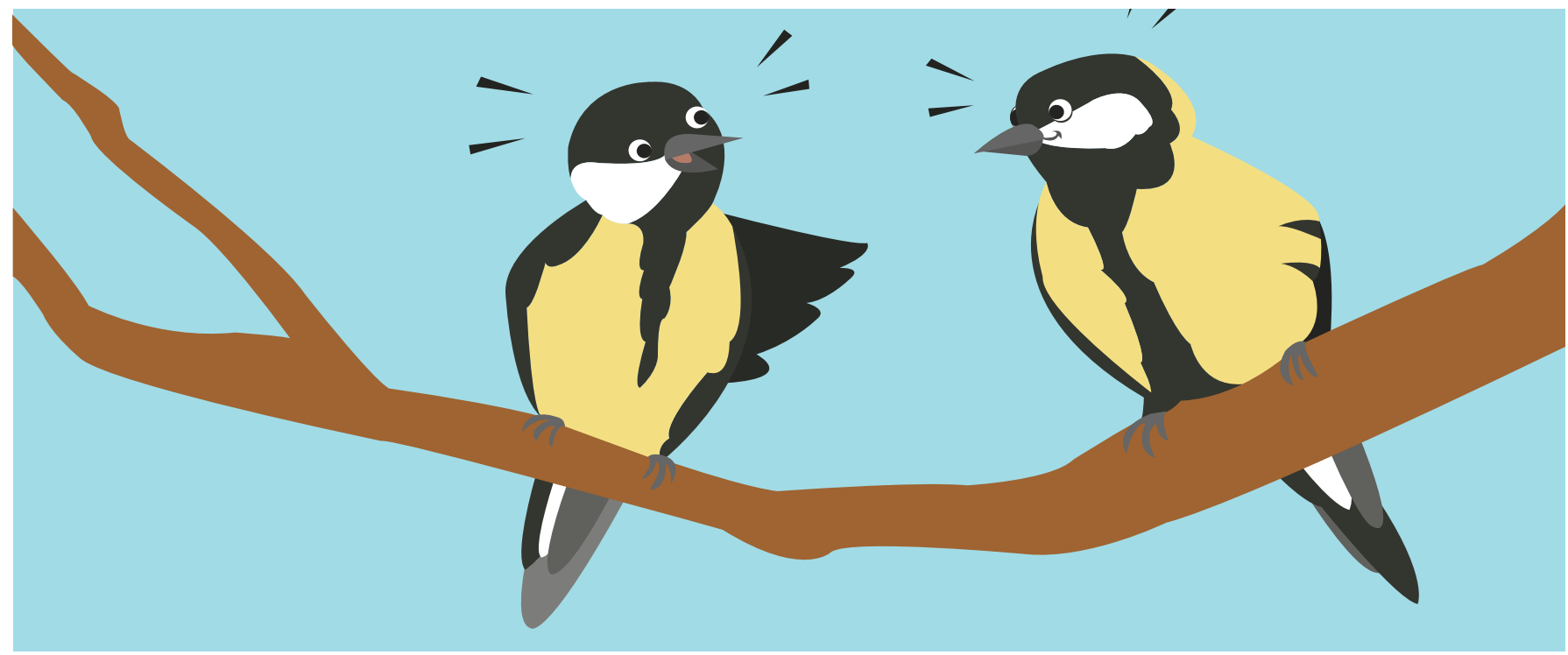

\title{
HOW DO BIRDS COPE WITH LOSING MEMBERS OF THEIR GROUP?
}

\section{Sarah L. Firth* and Josh A. Firth ${ }^{* *}$}

Department of Zoology, Edward Grey Institute, University of Oxford, Oxford, United Kingdom

REVIEWED BY:

DANIEL

AGE: 10

HELENE

AGE: 13
Have you ever wondered how animals might respond to losing a member of their group? Many human activities, like hunting or changing the environment animals live in, can cause the loss of individual animals. However, how this loss affects the remaining animals in a group is still widely unknown. We wanted to investigate this question, so we tracked wild birds known as great tits. These birds form small groups within their population, called flocks. By removing individual birds from the wild, we were able to monitor how birds responded to losing a flockmate. Interestingly, the birds that lost their flockmates responded by making new flockmates and also by spending more time with their previous flockmates. These findings show us that losing animals from a population can affect how the remaining animals behave. This research could help improve people's understanding of the effects of losing animals.

\section{POPULATION DECLINE IN ANIMALS}

A group of animals of the same species living in the same area is known as a population. Population decline happens when individuals within an animal 


\section{INTERACTION}

One individual coming into social contact with another.

\section{SOCIAL NETWORK}

A way of describing all the social contacts taking place between all the individuals in a population.

\section{FIGURE 1}

An example of a "social network" between animals. The blue lines between the birds show which birds interact with each other. The birds that interact with each other are called flockmates. The thickness of the lines shows how often they interact with each other: birds that have thick lines between them interact with each other a lot, those that have thin lines only interact sometimes, and those that are not joined by a line do not interact with each other. The bird in the middle was observed interacting with lots of other birds and is therefore described as very sociable. The bird most to the left was only seen with one other bird and, therefore, is described as not very sociable. population die or move to another location. Population decline can result from natural causes, such as predators eating the animals, or it can be due to humans [1]. For instance, humans use up land for houses, shops, factories, and farms. This can take up animals' habitats, meaning some animals might have to move out of their area or might even die due to lack of space or food, or increases in disturbance or other reasons. Another way humans can contribute to population decline is through hunting. This is a particularly big problem for rare or endangered species. So, we know how population decline occurs [1], but what impact does the loss of individual animals have on the remaining animals in the group?

Previous research has suggested that population decline can affect the remaining animals in a variety of ways. For example, if the animals within a population compete for food, then losing members of their population may mean more food for the animals that are left and less competition for it. On the other hand, if predators eat the animals, then having fewer animals around may mean the remaining animals are more likely to be eaten. Clearly, losing individuals from a population has an impact on the remaining animals, but we were interested to find out how it impacts the way the remaining animals interact with each other, as this is still widely unknown.

\section{ANIMAL SOCIAL INTERACTIONS}

Amazingly, recent advances in technology now allow us to track animals in the wild and record the social interactions taking places between individuals within a population. When we discuss a group of individuals and the social interactions taking place between them, you can imagine this as a web of connections. This is called a "social network" (see Figure 1). Animals that interact with lots of members of their group will have lots of connections and so belong in the middle of the social network. Animals that interact with only a few others will have fewer connections and belong on the edge of the social network.

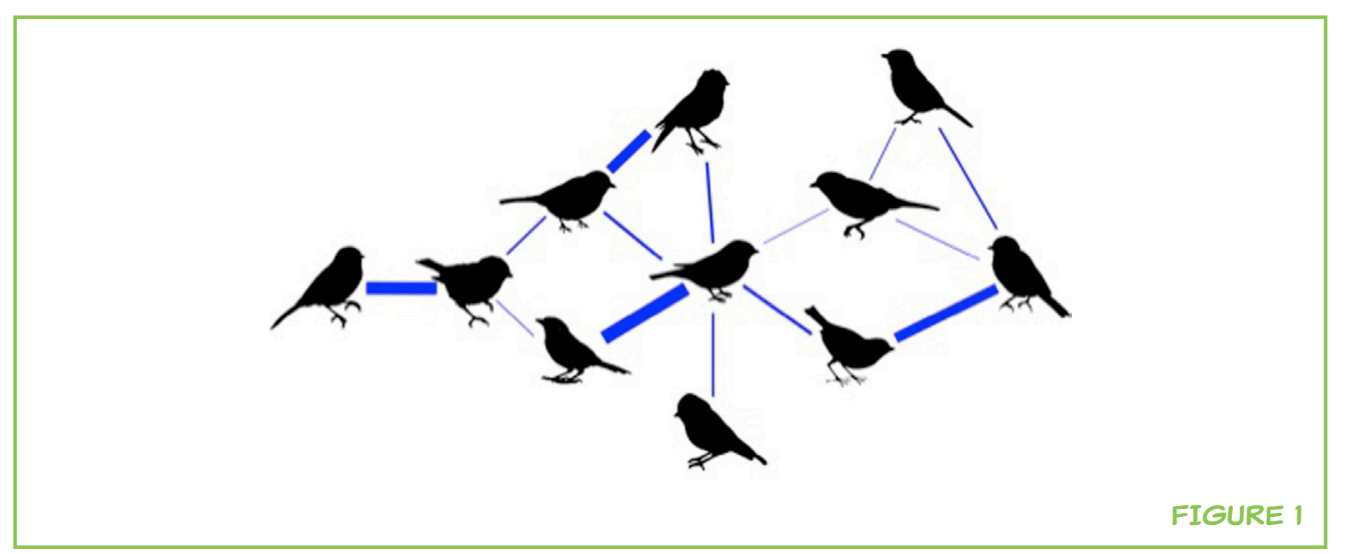




\section{CAPTIVITY}

When animals are kept and cared for by humans.

This includes keeping animals in laboratories, in zoos, or as pets.

\section{SIMULATION}

Using a computer to create a pretend situation to check what might happen in real life.

\section{RADIO-}

FREQUENCY IDENTIFICATION

Technology that allows us to automatically identify and track tags attached to animals or other objects.

The tags contain electronically stored information. Computerized readers record this information when the tag comes close to them.
Past studies have shown that animals' lives are affected by the number of social connections they have within their social network. Not only does the amount of connections they have affect their ability to influence other individuals but it also determines who they can learn new information from [2] or who they might catch a contagious disease from [3]. Therefore, social connections are important to animals, just as they are to humans. If a human loses a member of their group, especially one who is close to them, we would expect it to affect how they interact with others [4]. For example, if your best friend is away from school, this might change who you and your classmates spend your time with during break time. So, can we expect that wild animals will change their social interactions when losing a group member, just as you might?

\section{HOW MIGHT LOSING GROUP MEMBERS AFFECT SOCIAL INTERACTIONS?}

Previous work looking at how animals' social interactions might be affected by population decline has mainly been done using computers to simulate what might happen [5] in these situations. Other experiments that were carried out on animals in captivity showed that the results of the simulations did not match what happened in real life. But, even the experiments on captive animals cannot show how wild animals respond to losing group members under natural conditions in the wild. This is why experiments using wild animals are needed to properly understand how loss of individuals can affect the remaining animals' social interactions. This is what our work aimed to do using a population of wild birds called great tits, living in Wytham Woods in Oxford, UK. Biologists have studied this population for over 60 years. These birds form flocks during the winter and move around the woodland searching for food together $[2,6]$. Previous work has shown that these social interactions are important for many aspects of their lives, such as who they learn from [2], who they partner with to raise chicks, and who they choose to have as neighbors and build nests next to [6].

\section{TESTING HOW WILD BIRDS RESPOND TO LOSING FLOCKMATES}

Over the past 10 years, scientists have been catching wild great tits in Wytham Woods and attaching special tracking devices, called radiofrequency identification tags, to their legs (see Figure 2). These tags allow us to monitor which birds have visited any of the 65 computerized bird feeders in the woodland over the weekend and at what time. Birds that are recorded in the same flock are called flockmates. It is through looking at how much time each bird spends with their flockmates that we can see the number of social interactions they have and how strong these social connections are [6]. This gives us an indication of each bird's social behavior, 


\section{FIGURE 2}

A great tit from Wytham Woods, Oxford. The red circle added to the picture shows the radio-frequency identification tag that researchers put on the bird. This tag contains a unique code that is read by a computer whenever the bird visits a feeding station. This provides information on where the bird is feeding, when it is there, and which other birds it is there with. Photo credit: Molly Harwood.

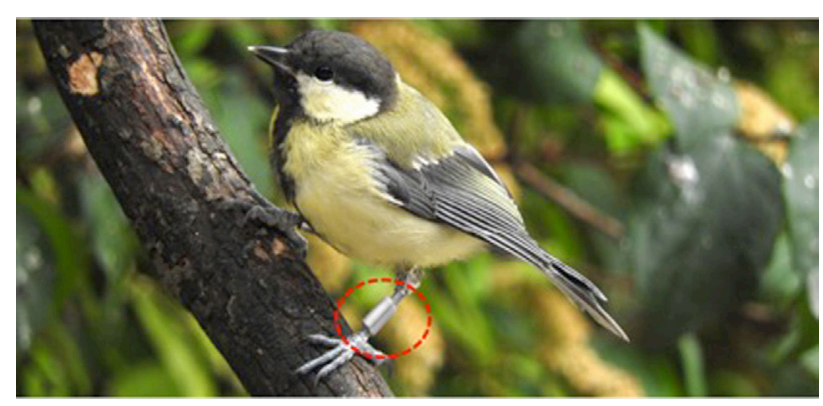

FIGURE 2

including how many social connections they hold to others and how many social interactions they engage in. This shows us each bird's position within the social network (see Figure 1).

We began the experiments in November, after measuring the birds' social interactions from September to October. We tracked a total of 542 great tits during this time. The experiments took place over 4 weeks. In each week, we caught some birds using a very thin but large net set up between two poles, called a mist net. We did this at two feeding stations in the middle of the week. Of the birds we caught, we randomly chose five or six of them and kept them in captivity over the weekend while we recorded the social interactions occurring between the remaining wild birds. This meant we could understand how the remaining birds interacted when they lost a flockmate.

\section{LOSING THEIR FLOCKMATES CAUSED BIRDS TO MAKE NEW FLOCKMATES}

Astoundingly, we found that birds made up for losing their flockmates not only by interacting more with their remaining flockmates but by also making new flockmates. Our results showed that the more flockmates we took away, the more the remaining birds made up for this by increasing their social interactions. For instance, we found that birds that had only one flockmate removed barely changed their behavior, but birds that had half of their flockmates removed generally gained five flockmates and significantly increased their time with others. This meant that even if their social connections were broken due to the removal of birds, the remaining birds quickly built new connections and strengthened existing connections instead.

To make sure that these changes in social behavior were definitely due to losing flockmates and not caused by disturbance through being caught, we compared the individuals who had their flockmates removed to those who just had their flockmates caught and immediately released. The results 
confirmed that the non-experiment group (the birds which had their flockmates caught and immediately released) showed no significant social behavior changes. Unlike the experiment group (the birds which had their flockmates removed), the non-experiment group did not make new connections or strengthen existing connections. This lets us be certain that the changes in the birds' social behavior is due to losing a flockmate and not general disturbance caused by the experiment. As well as this, we showed that the birds did not change any other behaviors, such as time spent feeding or how much they moved around the woods, in response to losing their flockmates. So, we learnt that birds adapt to the loss of flockmates by strengthening social relationships and making new ones.

You might be wondering what happened to the birds we removed from the woods? The good news is that the experiment did not have any long-term effects. Once released, the birds we removed quickly went back to hanging around with their previous flockmates and returned to their place in the social network. We now hope more experiments will be carried out to find out exactly how birds can return to their old social connections when released back into the woods.

\section{WHY DO BIRDS RESPOND THIS WAY TO LOSING THEIR FLOCKMATES?}

Now think, why might birds quickly make up for lost flockmates by increasing their social interactions with others? We know that social connections are very important to these birds over winter and affect almost every aspect of their lives. For example, birds use their flockmates to find out where food is [2]. So, gaining new flockmates after losing old ones might mean they can continue to learn the whereabouts of food from others. Birds also rely on their flockmates for protection against predators, so gaining new flockmates might help them avoid being eaten, even after they lose their old flockmates. Finally, the social relationships that birds form in the winter are also important later in their lives. In the spring, when these birds make a nest to raise their chicks, they often choose birds they have spent a lot of time with over the winter as their partner and also as their neighbors [6]. So, when a bird loses a flockmate during the winter, it might be important to quickly start forming new relationships, so that they have someone to breed with and nest next to during the spring.

In the natural world, great tits will often lose their flockmates, because lots of birds are eaten or move out of the woods on a regular basis. On average, only around half of the birds in the woods will be there from 1 year to the next year. So, these birds are probably used to losing their flockmates and this may be why they are so quick at making new relationships. It would now be interesting to look at how other species of animals, which are not 
as used to losing their group members, respond to loss. Interestingly, the results we found in this experiment are similar to a recent study looking at humans using Facebook [4]. The human research showed that people using Facebook responded to the death of their Facebook friends by increasing the amount of Facebook interactions (such as messages, comments, and "likes") with each other. So, similar to what we found with birds, humans also appear to increase their interactions with others in response to losing their group members too [4].

\section{HOW CAN OUR FINDINGS BE HELPFUL IN THE FUTURE?}

In today's world, lots of animal populations are experiencing declines and losing their members [1]. As mentioned earlier, humans often contribute to this problem. Therefore, it is especially important to try to understand how such loss affects the remaining individuals. This study is the first large experiment investigating how losing individuals affects the remaining animals' social interactions. So, any new information that we can learn is going to be helpful!

For instance, previous studies using computer simulations have suggested that losing group members may cause the group to break up [5]. Our findings suggest that this might not be the case, because animals can respond by increasing their social interactions with each other to fix this. By continuing to learn more about how animals respond to loss, we can get better at predicting what will happen in the future and how to best protect the remaining animals in declining populations.

Another example of how our findings could be useful is in considering how diseases spread. It has long been thought that removing certain animals from a population might help to stop a disease from spreading through that population [3]. The idea behind this was that removing the individuals who are most central to the social network will mean that the disease is unable to spread as quickly. But, our new discovery shows that this might not be the case, because animals can adjust to losing a group member by increasing their social connections with others and even by connecting with new members. So, attempting to stop disease spread by removing the socially connected animals might not work, because the remaining animals may make more connections and the disease might spread just as easily as it would have before any animals were removed.

We hope that our research will inspire new investigations into how all kinds of different species cope with losing their group members. This will allow us to learn more about the natural world and the animals that live in it. By learning more about animals and understanding their behaviors, we can find even better ways to look out for them and protect them [1]. 


\section{ORIGINAL SOURCE ARTICLE}

Firth, J. A., Voelkl, B., Crates, R. A., Aplin, L. M., Biro, D., Croft, D. P., and Sheldon, B. C. 2017. Wild birds respond to flockmate loss by increasing their social network associations to others. Proc. R. Soc. B 284, 20170299. doi:10.1098/rspb.2017.0299

\section{REFERENCES}

1. WWF. 2014. Living Planet Report 2014. Gland, Switzerland: World Wildlife Fund. Available at: http://wwf.panda.org/wwf_news/?231893/Living-Planet-Report-2014

2. Firth, J. A., Sheldon, B. C., and Farine, D. R. 2016. Pathways of information transmission among wild songbirds follow experimentally imposed changes in social foraging structure. Biol. Lett. 12, 20160144. doi:10.1098/rsbl.2016.0144

3. Silk, M. J., Croft, D. P., Delahay, R. J., Hodgson, D. J., Boots, M., Weber, N., et al. 2017. Using social network measures in wildlife disease ecology, epidemiology, and management. Bioscience 67, 245-257. doi:10.1093/biosci/biw175

4. Hobbs, W. R., and Burke, M. K. 2017. Connective recovery in social networks after the death of a friend. Nat. Hum Behav 1, 0092. doi:10.1038/s41562-017-0092

5. Lusseau, D. 2003. The emergent properties of a dolphin social network. Proc. $R$. Soc. Lond. B 270, S186-S188. doi:10.1098/rsbl.2003.0057

6. Firth, J. A., and Sheldon, B. C. 2017. Social carry-over effects underpin transseasonally linked structure in a wild bird population. Ecol. Lett. 20, 60-69. doi:10.1111/ele.12669

SUBMITTED: 20 July 2017; ACCEPTED: 09 February 2018; PUBLISHED ONLINE: 20 March 2018.

EDITED BY: Sophie Von Der Heyden, University of Stellenbosch, South Africa

CITATION: Firth SL and Firth JA (2018) How Do Birds Cope with Losing Members of Their Group? Front. Young Minds 6:8. doi:10.3389/frym.2018.00008

CONFLICT OF INTEREST STATEMENT: The authors declare that the research was conducted in the absence of any commercial or financial relationships that could be construed as a potential conflict of interest.

COPYRIGHT @ 2018 Firth and Firth. This is an open-access article distributed under the terms of the Creative Commons Attribution License (CC BY). The use, distribution or reproduction in other forums is permitted, provided the original author(s) and the copyright owner are credited and that the original publication in this journal is cited, in accordance with accepted academic practice. No use, distribution or reproduction is permitted which does not comply with these terms. 


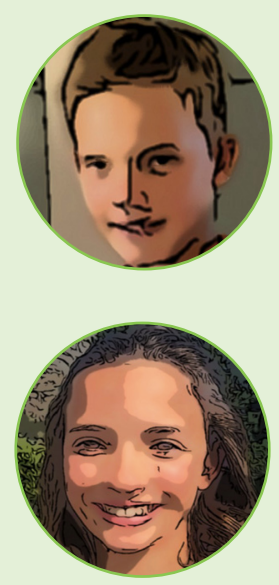

\section{REVIEWED BY}

\section{DANIEL, AGE: 10}

I have grown up in Africa and been lucky enough to spend many months in the bush. When we are not watching animals or birds, I love to sail and run and at school I really enjoy science and maths. I also love engineering and flying and would like to be an aerospace engineer!

\section{HELENE, AGE: 13}

I am 13 years old and live in the Western Cape in South Africa. My biggest hobby is horse riding and hanging out at the stables. At school I am learning to speak five languages: English, Afrikaans, isiXhosa, Spanish, and German, which is very cool. I also love science and spending time with my family in the bushveld.

\section{AUTHORS}

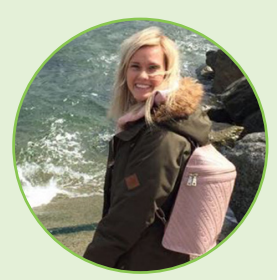

\section{SARAH L. FIRTH}

Sarah L. Firth is a primary school teacher trained at Sheffield Hallam University. Among other subjects, she has worked as Head of Science, and her interests lie primarily in communicating new concepts to children. She holds a special interest in animals and biodiversity, as well as new approaches aimed at improving children's appreciation and knowledge of the natural world. *sarahfirth.psy@gmail.com

\section{JOSH A. FIRTH}

Josh A. Firth is a Postdoctoral Research Fellow at the University of Oxford. His interests mainly lie in understanding the social behavior of animals and how this affects other aspects of their lives. To do this, he uses lots of data obtained by tracking many individuals, as well as experiments carried out in the wild. He is particularly fond of working with birds and observing their behavior. **joshua.firth@zoo.ox.ac.uk 